\title{
General Psychiatry Psychometric properties of the Urdu version of the Hospital Anxiety and Depression Scale (HADS) among pregnant women in Abbottabad, Pakistan
}

\author{
Fahad Saqib Lodhi, ${ }^{1,2}$ Aymen M Elsous, ${ }^{3,4}$ Saadia Irum, ${ }^{5}$ Adeel Ahmed Khan (D) , \\ Unaib Rabbani ${ }^{7}$
}

To cite: Lodhi FS, Elsous AM, Irum S, et al. Psychometric properties of the Urdu version of the Hospital Anxiety and Depression Scale (HADS) among pregnant women in Abbottabad, Pakistan. General Psychiatry 2020;33:e100276. doi:10.1136/ gpsych-2020-100276

- Additional material is published online only. To view, please visit the journal online (http://dx.doi.org/10.1136/ gpsych-2020-100276).

Received 16 May 2020 Revised 16 June 2020 Accepted 02 July 2020

Check for updates

(C) Author(s) (or their employer(s)) 2020. Re-use permitted under CC BY-NC. No commercial re-use. See rights and permissions. Published by BMJ.

For numbered affiliations see end of article.

Correspondence to

Professor Fahad Saqib Lodhi; fahadsaqiblodhi@hotmail.com

\section{ABSTRACT}

Background The Hospital Anxiety and Depression Scale (HADS) is a widely used instrument to measure anxiety and depression symptoms.

Aims This study aimed to translate, validate and test the applicability of the Urdu version of the Hospital Anxiety and Depression Scale (HADS/UV) among pregnant women.

Methods The original English version of the HADS was translated into Urdu by three bilingual experts and retranslated to English using the forward-backward approach. The questionnaire was administered to a sample of 200 pregnant women availing obstetrics and gynaecology services for routine prenatal checkups of Ayub Teaching Hospital, Abbottabad, Pakistan. Psychometric properties of the instrument, including reliability (internal consistency, test-retest analysis and interitems correlation), were tested. Face and content validity were also assessed. Content Validity Index (CVI) was determined using the average approach and ItemLevel Content Validity Index (I-CVI) and Scale-Level Content Validity Index (S-CVI) were calculated accordingly. Construct validity was examined through exploratory factor analysis.

Results Cronbach's alpha coefficient has been found to be 0.82 for the anxiety subscale and 0.64 for the depression subscale, while overall alpha of the HADS/ UV is 0.84 . The Urdu version is content valid, and the SCVI of anxiety subscale, depression subscale and HADS/ UV are 0.947, 948 and 0.947 , respectively. Test-retest reliability is 0.884 and 0.934 as measured by Pearson correlation and intraclass correlation, respectively. HADS/ UV items correlated positively with the whole scale $(p<0.001)$. Factor analysis with varimax rotation revealed that two factors explained $42.75 \%$ of the variance. Items' distribution was quite similar to the original HADS.

Conclusion The HADS/UV is a psychometrically sound instrument with satisfactory measurement, including good internal consistency. The instrument shows promise to be a sound tool to assess anxiety and depression in pregnancy.

\section{INTRODUCTION}

Screening tools are used in epidemiological and clinical studies, which are often conducted among various population groups.
This requires a culturally understandable and valid translation of the tool. ${ }^{12}$ Translating a tool from its original language could pose problems as the translated version may lose the meaning intended in the original version. ${ }^{23}$ This issue of translating a questionnaire into other languages has been extensively discussed in psychology literature. ${ }^{45}$

The translated version of the questionnaire is expected to be as close as possible to the original and serves the same purpose. ${ }^{6}$ However, in real life, there is conflict between the two as literal translation often gives a different meaning. In the literature, there is a debate on which of these two is to be followed. ${ }^{15}$

The Hospital Anxiety and Depression Scale (HADS) is a widely used tool to screen anxiety and depression among various patient groups. The HADS is a 14-item scale with two subsets of seven questions developed to measure anxiety and depression. This tool has been found to be reliable and valid for assessment of anxiety and depression among various ethnic groups. A number of researchers across the world have translated and validated HADS in different languages, such as Arabic, Chinese, Dutch, French, German, Persian and Spanish. ${ }^{78}$ In South Asia, HADS has been translated into Urdu, Malayalam, Nepali, Punjabi and Pushtoo. ${ }^{9-14}$

The HADS has been used extensively in the recent past to assess anxiety and depression among pregnant women. However, it focused on women with complicated pregnancies. Little research was conducted among women with normal pregnancies. Recently, only one study from Lahore, Pakistan, among prenatal and perinatal women validated the Urdu version of the Hospital Anxiety and Depression Scale (HADS/UV). ${ }^{12}$ Given the high burden of mental disorders among pregnant 
women and the scarcity of literature about validity and reliability of screening tool in the local context, we aimed to assess the psychometric properties of the HADS among pregnant women in the Abbottabad province, Pakistan.

\section{MATERIALS AND METHODS \\ Study design and setting}

This was a methodological study to examine the psychometric soundness of HADS/UV. A hospital-based crosssectional design was conducted among pregnant women attending the gynaecology outpatient departments (OPDs) for their routine antenatal check-ups from April 2019 till August 2019 at Ayub Teaching Hospital, Abbottabad, Khyber Pakhtunkhwa province, Pakistan. Ayub Medical and Teaching Institution Abbottabad is a 1000-bed tertiary care teaching hospital and the largest healthcare facility of Northern Pakistan and provides major healthcare facilities to the general population. The obstetrics and gynaecology department is well equipped with advanced diagnostic and therapeutic facilities, along with trained staff. ${ }^{15}$

During the study period, 220 women attending routine antenatal care at Ayub Teaching Hospital were approached and encouraged to participate in the study. Women who consented to participate in the study were interviewed using a structured questionnaire comprising sociodemographic, family structure and relationship variables and maternal characteristics followed by the HADS.

\section{Sample and sampling}

A convenience sampling of 200 pregnant women finally completed the interview, while 20 women discontinued the interview and had missing data. Inclusion criteria were pregnancy in any trimester; willingness to participate; and not being diagnosed with psychological disorders before the commencement of the study, including anxiety and depression. A systematic presentation of the study procedure is shown in figure 1 .

\section{Study tool}

Hospital Anxiety Depression Scale

The HADS is a commonly used instrument in a hospital setting originally developed by Zingmond and Snaith. ${ }^{16}$ It is used to determine anxiety and depression levels in different populations with an established validity and reliability. ${ }^{16} 17$ The HADS is a 14 -item questionnaire consisting of two subscales, one for depression symptoms (Hospital Anxiety and Depression Scale Depression Subscale [HADS-D]) and one for symptoms of anxiety (Hospital Anxiety and Depression Scale Anxiety Subscale [HADS-A]). Depressive and anxiety symptoms during the previous week are reported on a Likert scale ranging from ' 0 ' (not at all) to ' 3 ' (most of the time). The standard scoring algorithm was used=sum of items (anxiety) $1^{*}, 3^{*}$, $5^{*}, 7,9,11^{*}, 13^{*}$ and depression=sum of items $2,4,6^{*}, 8^{*}$, $10^{*}, 12,14$, where starred items were reverse record. Total scores on these subscales ranged from 0 to 21. A score
Total number of patients in antenatal and outpatient clinics were $\mathbf{2 0 0 0 0}$ in gynecology and obstetrics department from April to August, 2019.

Inclusion criteria:

- Pregnancy in any trimester - Willingness to participate - Not diagnosed with psychological disorder before commencing the study including anxiety and depression.

A convenience sample of 220 pregnant women was taken for our study and invited to participate.

20 participants were excluded:

-12 had missing data

-8 discontinued interview

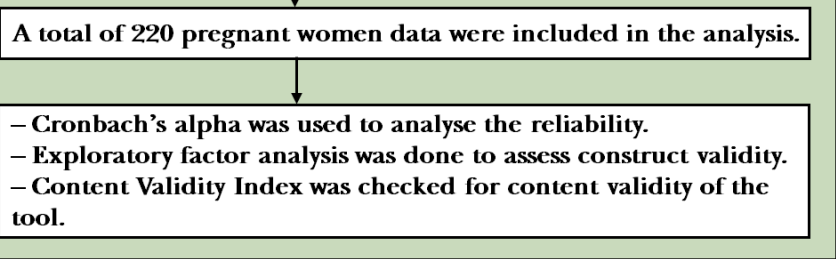

Figure 1 Systematic presentation of study procedure.

of $0-7$ is considered as normal, $8-10$ as borderline and $11-21$ as either anxious or depressed. ${ }^{17}$

\section{Forward-backward translation}

Translation of the HADS from English to Urdu was independently done by three bilingual experts using the forward-backward method. The resulting translated draft was sent to experts in the health sector with experience in survey development. Arguments were made on many translations. The word 'wound up' in item 1 'A1', 'slowed down' in item 8 ' $\mathrm{D} 4$ ', 'butterflies' in item 9 'A5' and 'to be on the move' in item 11 'A6' received extensive discussion because of variations in translations. The research team focused on conceptual rather than linguistic translation, and therefore consistency was reached and the final draft was established. The provisional version was then sent for backward translation and given to two independent experts who had no previous knowledge of the questionnaire. ${ }^{18}$ The backward translation is a familiar approach because it gives an indication of semantic equivalence and boosts validity of instruments.

\section{STATISTICAL ANALYSIS}

\section{Test-retest reliability}

A pilot test was conducted to ensure the items' validity, sequence of questions, complete understanding and average time taken by participants for the interview. We conducted the pilot study before the start of the original survey, the questionnaire was tested-retested on 20 pregnant women attending the gynaecology OPDs for their routine antenatal check-ups, and these data were not included in the final analysis. Participants were requested to complete the translated HADS, along with the social demographic questionnaire, and the same questionnaire 
was provided to them again after a time interval of 2 weeks. For analysis, we expected the Cronbach alpha equal or greater than 0.70 . Test-retest reliability signifies score stability over a time. Internal consistency was verified by examining the Cronbach coefficient alpha of $>0.65$ for HADS-A, HADS-D and the total HADS.

\section{Reliability analysis}

We conducted a reliability analysis of the HADS total, HADS-A and HADS-D subscales to ensure internal consistency. A Cronbach alpha reliability coefficient was considered satisfactory if the value was equal or greater than $0.65 .^{19}$

\section{Construct validity}

Exploratory factor analysis (EFA) was examined on the 14 items of the HADS by means of survey among 200 pregnant women who attended routine antenatal care. Suitability of data and sampling adequacy was examined through assessment of Kaiser Meyer Olkin (KMO) > 0.6 and Bartlett test for sphericity. EFA was performed with varimax rotation and items loaded $\geq 0.3$ were included.

\section{Content Validity Index}

Content validity was checked to ascertain whether the questionnaire's content is appropriate and the relevance of study purpose. A convenient sample of 10 health experts received the HADS/UV and were asked to rate the relevancy of items to its subscale using the 4-point Likert scale: 1 = not relevant, 2 = somewhat relevant, 3 $=$ relevantand $4=$ highly relevant. An item that received a score of 1 or 2 was considered 'content invalid', while a rating of 3 or 4 was considered 'content valid'. Eight raters responded and Item-Level Content Validity Index (I-CVI) and Scale-Level Content Validity Index (S-CVI) were calculated accordingly using the average approach. CVI was calculated as the proportion of items that had ratings of 3 or 4 by the rating experts.

\section{Data collection procedure}

Informed consent was taken by the researcher before the start of the interview from pregnant women who visited the gynaecological OPDs. Participants were interviewed by gynaecological and obstetrical physicians. Two days of interviewing skills training were given to data collectors due to the sensitive nature of questions asked during the interview. The interview was conducted in a separated room. The average time taken by the each participant was $20-25 \mathrm{~min}$. Written informed consent was provided by each of the 200 participants who agreed to take part.

\section{RESULTS}

\section{Characteristics of the study participants}

The demographic, obstetric and gynaecological characteristics of participating women are presented in table 1. A total of 200 pregnant women were included, and the mean age was 26.7 (5.0) years. Half of the women (102 $(51 \%))$ were residents in urban areas; $115(57 \%)$ had a
Table 1 Sociodemographic and obstetric characteristics of participants $(n=200)$

\begin{tabular}{|c|c|c|}
\hline Variables & Frequency (n) & Percentage (\%) \\
\hline $\begin{array}{l}\text { Respondent age (years), } \\
\text { mean (SD) }\end{array}$ & $26.7(5.0)$ & \\
\hline$\leq 30$ & 151 & 75.5 \\
\hline$>30$ & 49 & 24.5 \\
\hline \multicolumn{3}{|l|}{ Type of residence } \\
\hline Urban & 102 & 51 \\
\hline Rural & 98 & 49 \\
\hline Gravida mean (SD) & $2.48(2.10)$ & \\
\hline$\leq 2$ & 115 & 57 \\
\hline$>2$ & 85 & 43 \\
\hline Parity mean (SD) & $1.65(1.69)$ & \\
\hline$\leq 1$ & 121 & 60.5 \\
\hline$>1$ & 79 & 39.5 \\
\hline \multicolumn{3}{|l|}{ Family number in household } \\
\hline $1-5$ & 52 & 26 \\
\hline $6-10$ & 99 & 44.5 \\
\hline$>10$ & 49 & 29.5 \\
\hline \multicolumn{3}{|l|}{ History of abortion } \\
\hline Yes & 31 & 15.5 \\
\hline No & 169 & 84.5 \\
\hline \multicolumn{3}{|l|}{ Diabetes mellitus } \\
\hline Yes & 11 & 5.5 \\
\hline No & 189 & 94.5 \\
\hline \multicolumn{3}{|l|}{ Hypertension } \\
\hline Yes & 28 & 14.0 \\
\hline No & 172 & 86.0 \\
\hline \multicolumn{3}{|l|}{ Education level } \\
\hline No formal education & 55 & 27.5 \\
\hline Primary (up to grade 5) & 38 & 19.0 \\
\hline $\begin{array}{l}\text { Secondary (up to } \\
\text { grade 12) }\end{array}$ & 73 & 36.5 \\
\hline $\begin{array}{l}\text { Tertiary (up to grade } 16 \\
\text { or above) }\end{array}$ & 34 & 17.0 \\
\hline \multicolumn{3}{|c|}{ Household income in Pakistani rupee } \\
\hline$\leq 20000$ & 117 & 58.5 \\
\hline$>20000$ & 83 & 41.5 \\
\hline \multicolumn{3}{|l|}{ Family system } \\
\hline Nuclear & 40 & 20 \\
\hline Joint & 159 & 79.5 \\
\hline
\end{tabular}

history of at most two gravida; and 79 (39.5\%) had a history of at least two deliveries. History of previous abortions was reported in 31 women (15.5\%). One-third completed up to elementary school and $34(17 \%)$ completed university level, while $55(27.5 \%)$ could not have formal education. Twenty-eight (14\%) and 11 women (5.5\%) were reported to have hypertension and diabetes, respectively. Most of 
Table 2 Content Validity Index of Hospital Anxiety and Depression Scale items

\begin{tabular}{|c|c|c|c|c|c|}
\hline & $\begin{array}{l}\text { Giving rating of } 3 \\
\text { or } 4 \text { out of eight } \\
\text { experts (n) }\end{array}$ & $\mathrm{I}-\mathrm{CVI} /$ average & $\mathrm{pc}^{*}$ & $K^{\star}+$ & Interpretation $\ddagger$ \\
\hline I feel tense or 'wound up'. & 8 & 1 & 0.004 & 1.00 & Excellent \\
\hline $\begin{array}{l}\text { I get a sort of frightened feeling, like 'butterflies' } \\
\text { in the stomach. }\end{array}$ & 8 & 1 & 0.004 & 1.00 & Excellent \\
\hline $\begin{array}{l}\text { I get a sort of frightened feeling as if something } \\
\text { awful is about to happen. }\end{array}$ & 8 & 1 & 0.004 & 1.00 & Excellent \\
\hline I feel restless as I have to be on the move. & 6 & 0.75 & 0.109 & 0.72 & Good \\
\hline Worrying thoughts go through my mind. & 8 & 1 & 0.004 & 1.00 & Excellent \\
\hline I get sudden feelings of panic. & 8 & 1 & 0.004 & 1.00 & Excellent \\
\hline I can sit at ease and feel relaxed. & 7 & 0.88 & 0.031 & 0.88 & Excellent \\
\hline \multicolumn{6}{|l|}{ Anxiety (S-CVI/average: 0.947) } \\
\hline I feel as if I am slowed down. & 8 & 1 & 0.004 & 1.00 & Excellent \\
\hline I still enjoy the things I used to enjoy. & 7 & 0.88 & 0.031 & 0.88 & Excellent \\
\hline I have lost interest in my appearance. & 8 & 1 & 0.004 & 1.00 & Excellent \\
\hline I can laugh and see the funny side of things. & 7 & 0.88 & 0.031 & 0.88 & Excellent \\
\hline I look forward with enjoyment to things. & 7 & 0.88 & 0.031 & 0.88 & Excellent \\
\hline I feel cheerful. & 8 & 1 & 0.004 & 1.00 & Excellent \\
\hline $\begin{array}{l}\text { I can enjoy a good book or radio or TV } \\
\text { programme. }\end{array}$ & 8 & 1 & 0.004 & 1.00 & Excellent \\
\hline
\end{tabular}

Depression (S-CVI/average: 0.948)

*: pc (probability of a chance occurrence) was computed using the formula: $\mathrm{pc}=[\mathrm{N} ! / \mathrm{A} !(\mathrm{N}-\mathrm{A}) !] \times 0.5 \mathrm{~N}$, where $\mathrm{N}=$ number of experts and $A=$ number agreeing on good relevance.

$\dagger \mathrm{k}^{*}$ : kappa designating agreement on relevance: $\mathrm{k}^{*}=\left(\mathrm{I}-\mathrm{CVI} \_\mathrm{pc}\right) /\left(1 \_\mathrm{pc}\right)$.

$\ddagger$ : Evaluation criteria for kappa using guidelines described in Cicchetti (1984) $)^{35}$

I-CVI, Item-Level Content Validity Index; S-CVI, Scale-Level Content Validity Index.

the respondents belonged to joint family systems (159 $(79.5 \%))$.

\section{Assessment of validity}

Regarding face validity, reviewers were satisfied with questionnaire appearance. Moreover, questions were clear and easy to understand; however, we made some changes for questions 3 and 4 after the feedback received from the reviewers and made it simpler. For content validity, the I-CVI and S-CVI scores were calculated accordingly. The I-CVI scores of anxiety and depression items ranged between 0.75 and 1.0 and between 0.88 and 1.0, respectively. The S-CVI scores of anxiety and depression items were 0.947 and 0.948 , respectively. For HADS, the CVI was 0.947 (table 2).

Analysis of reliability involved assessment of the Cronbach alpha coefficient. The value was adequate $(>0.7)$, and after removal of each item, the Cronbach alpha did not reveal any major deviation in the overall internal consistency of the HADS. Majority of the corrected item-total correction analysis was above 0.4; however, the lowest value was in the statement 'I can enjoy a good book or radio or TV programme', and the value was 0.15 (table 3).

\section{Internal consistency reliability analysis}

The anxiety and depression subscale had a Cronbach alpha equal to 0.82 and 0.64 , respectively. However, the Cronbach alpha value for whole scale was good $(\alpha=0.84)$. All anxiety items showed a significant correlation with the anxiety subscale (range $0.56-0.77, \mathrm{p}<0.001$ ). Similarly, depression items showed a significant correlation with the depression subscale (range 0.39-0.70, $\mathrm{p}<0.001$ ). Furthermore, items of HADS also showed a significant correlation with the full scale (range 0.27-0.75, p<0.001) (table 4). The two subscales correlated significantly with each other (Pearson's coefficient $r=0.894, \mathrm{p}<0.001$ ). In turn, each subscale showed a significant good correlation with the full scale $(r=0.930$ and $r=0.894, p<0.001)$ for the anxiety and depression subscales, respectively.

\section{Exploratory factor analysis}

Prior to factor extraction, sampling adequacy was checked to ensure suitability for factor analysis. The Kaiser-MeyerOlkin (KMO) and the Bartlett test of sphericity (BTS) showed adequate sampling. The KMO yielded an index of 0.847 and high significant BTS $\left(\chi^{2}=800.327, \mathrm{df}=91\right.$, $\mathrm{p}<0.001)$. The number of factors were assessed using eigenvalues greater than 1 , which suggested two-factor solution and explained $42.75 \%$ of the total response 
Table 3 HADS test-retest reliability and scale variance analysis $(n=200)$

\begin{tabular}{|c|c|c|c|c|}
\hline & $\begin{array}{l}\text { Scale mean if } \\
\text { items deleted }\end{array}$ & $\begin{array}{l}\text { Scale variance if } \\
\text { item deleted }\end{array}$ & $\begin{array}{l}\text { Corrected item, } \\
\text { total correlation }\end{array}$ & $\begin{array}{l}\text { Cronbach's alpha if } \\
\text { item deleted }\end{array}$ \\
\hline A: I feel tense or 'wound up'. & 16.71 & 45.96 & 0.59 & 0.83 \\
\hline D: I still enjoy the things I used to enjoy. & 17.06 & 49.66 & 0.39 & 0.84 \\
\hline $\begin{array}{l}\text { A: I get a sort of frightened feeling as if something } \\
\text { awful is about to happen. }\end{array}$ & 16.69 & 45.25 & 0.62 & 0.82 \\
\hline D: I can laugh and see the funny side of things. & 16.70 & 46.91 & 0.56 & 0.83 \\
\hline A: Worrying thoughts go through my mind. & 16.99 & 47.10 & 0.57 & 0.83 \\
\hline D: I feel cheerful. & 17.29 & 46.64 & 0.60 & 0.82 \\
\hline A: I can sit at ease and feel relaxed. & 16.79 & 47.94 & 0.53 & 0.83 \\
\hline D: I feel as if I am slowed down. & 16.84 & 50.40 & 0.33 & 0.84 \\
\hline $\begin{array}{l}\text { A: I get a sort of frightened feeling, like 'butterflies' } \\
\text { in the stomach. }\end{array}$ & 16.83 & 49.64 & 0.46 & 0.83 \\
\hline D: I have lost interest in my appearance. & 17.20 & 50.81 & 0.28 & 0.84 \\
\hline A: I feel restless as I have to be on the move. & 16.88 & 48.46 & 0.49 & 0.83 \\
\hline D: I look forward with enjoyment to things. & 17.06 & 47.95 & 0.50 & 0.83 \\
\hline A: I get sudden feelings of panic. & 16.77 & 46.91 & 0.69 & 0.82 \\
\hline $\begin{array}{l}\text { D: I can enjoy a good book or radio or TV } \\
\text { programme. }\end{array}$ & 16.63 & 52.33 & 0.15 & 0.85 \\
\hline
\end{tabular}

A, anxiety; D, depression.

variance. The two-factor solution is the most frequently reported one in literature. The first and second factors explained $34.97 \%$ and $7.78 \%$ of the variability of data, respectively (table 5 ).

Table 4 Correlations between anxiety and depression subscales and total Hospital Anxiety and Depression Scale $(n=200)$

\begin{tabular}{|c|c|c|c|}
\hline Item & $\begin{array}{l}\text { Anxiety } \\
\text { subscale }\end{array}$ & $\begin{array}{l}\text { Depression } \\
\text { subscale }\end{array}$ & $\begin{array}{l}\text { Full } \\
\text { scale }\end{array}$ \\
\hline A1 (tense) & $0.77^{*}$ & 0.43 & $0.67^{*}$ \\
\hline A2 (frightened) & $0.74^{*}$ & 0.53 & $0.49^{*}$ \\
\hline A3 (worrying thought) & $0.73^{*}$ & 0.42 & $0.70^{*}$ \\
\hline A4 (feel relaxed) & $0.63^{*}$ & 0.48 & $0.64^{*}$ \\
\hline $\begin{array}{l}\text { A5 ('butterflies' in the } \\
\text { stomach) }\end{array}$ & $0.56^{*}$ & 0.42 & $0.65^{\star}$ \\
\hline A6 (restless) & $0.65^{\star}$ & 0.38 & $0.68^{*}$ \\
\hline A7 (panic attack) & $0.75^{\star}$ & 0.60 & $0.62^{*}$ \\
\hline $\begin{array}{l}\text { D1 (enjoy the things I } \\
\text { used to) }\end{array}$ & 0.34 & $0.58^{*}$ & $0.44^{*}$ \\
\hline $\begin{array}{l}\text { D2 (laugh and see the } \\
\text { funny side) }\end{array}$ & 0.50 & $0.70^{*}$ & $0.54^{*}$ \\
\hline D3 (cheerful) & 0.58 & $0.67^{*}$ & $0.30^{*}$ \\
\hline D4 (slowed down) & 0.33 & $0.48^{*}$ & $0.58^{*}$ \\
\hline $\begin{array}{l}\text { D5 (lost interest in } \\
\text { appearance) }\end{array}$ & 0.24 & $0.50^{*}$ & $0.59^{*}$ \\
\hline $\begin{array}{l}\text { D6 (look forward with } \\
\text { enjoyment) }\end{array}$ & 0.49 & $0.60^{*}$ & $0.75^{\star}$ \\
\hline $\begin{array}{l}\text { D7 (enjoy a good book, } \\
\text { radio or TV) }\end{array}$ & 0.14 & $0.39^{*}$ & $0.27^{*}$ \\
\hline
\end{tabular}

*:All correlations are significant at the 0.001 level.

\section{DISCUSSION}

\section{Main findings}

In this study, the HADS was validated on a sample of Pakistani pregnant women living in the district of Abbottabad. Our findings are of clinical importance in terms of validation of a screening tool for anxiety and depression. The HADS/UV proved to be acceptable for pregnant women.

The language of the original English questionnaire was highly metaphorical, and some items had to be carefully translated to adapt to the Urdu language of the Pakistani population. Translation of the HADS items faced some problems, and some items were retranslated at least twice, especially item $8 \mathrm{D} 4$, item $9 \mathrm{~A} 5$ and item $11 \mathrm{~A} 6$, because of ambiguity of words. Ambiguity was also noticed with the Polish ${ }^{20}$ and Malayalam versions. ${ }^{14}$ In our opinion, the translation was sufficient; however, further scrutiny of the meaning is suggested to match with the Urdu language and local context.

The original research of HADS tested its psychometric soundness on a group of hospitalised patients who suffered from different diseases. The scale is proven to be valid and reliable for other groups of patients as well: for oncology, ${ }^{21}{ }^{22}$ HIV-infected patients, ${ }^{23}$ hospitalised elderly, ${ }^{24}$ gynaecology patients, ${ }^{12}{ }^{14}$ patients with coronary artery diseases,${ }^{25}$ patients in the emergency department ${ }^{26}$ and among patients in primary healthcare. ${ }^{27}$ In turn, our study contributes to the body of knowledge about irregularities of psychometric findings of HADS noticed in the literature ${ }^{28}$ when it is applied on patients with chronic diseases to others who suffer from physiological changes during pregnancy.

With regard to content validity, the CVI of HADS items revealed high and excellent agreement among experts 
Table 5 Exploratory factor analysis of HADS items with varimax rotation matrix $(n=200)$

\begin{tabular}{|c|c|c|}
\hline HADS items & $\mathbf{F 1}$ & $\mathbf{F 2}$ \\
\hline I feel tense or 'wound up'. & 0.686 & 0.274 \\
\hline $\begin{array}{l}\text { I still enjoy the things I used to } \\
\text { enjoy. }\end{array}$ & 0.058 & 0.652 \\
\hline $\begin{array}{l}\text { I get a sort of frightened feeling } \\
\text { as if something awful is about to } \\
\text { happen. }\end{array}$ & 0.675 & 0.307 \\
\hline $\begin{array}{l}\text { I can laugh and see the funny side } \\
\text { of things. }\end{array}$ & 0.254 & 0.698 \\
\hline $\begin{array}{l}\text { Worrying thoughts go through my } \\
\text { mind. }\end{array}$ & 0.713 & 0.178 \\
\hline I feel cheerful. & 0.583 & 0.386 \\
\hline I can sit at ease and feel relaxed. & 0.363 & 0.539 \\
\hline I feel as if I am slowed down. & 0.225 & 0.374 \\
\hline $\begin{array}{l}\text { I get a sort of frightened feeling like } \\
\text { 'butterflies' in the stomach. }\end{array}$ & 0.255 & 0.550 \\
\hline $\begin{array}{l}\text { I have lost interest in my } \\
\text { appearance. }\end{array}$ & 0.075 & 0.431 \\
\hline $\begin{array}{l}\text { I feel restless as I have to be on the } \\
\text { move. }\end{array}$ & 0.796 & 0.004 \\
\hline $\begin{array}{l}\text { I look forward with enjoyment to } \\
\text { things. }\end{array}$ & 0.278 & 0.592 \\
\hline I get sudden feelings of panic. & 0.639 & 0.451 \\
\hline $\begin{array}{l}\text { I can enjoy a good book, radio or } \\
\text { TV programme. }\end{array}$ & 0.150 & 0.110 \\
\hline$\%$ of variance: $42.75 \%$ & $34.97 \%$ & $7.78 \%$ \\
\hline
\end{tabular}

Bold indicates significant factor loading at level above 0.30 . HADS, Hospital Anxiety and Depression Scale.

( $\mathrm{k} \geq 0.88$ ), indicating good content validity, except for item $11 \mathrm{~A} 6(\mathrm{k}=0.72)$, which is below the recommended value $(\mathrm{k}>0.75) .{ }^{29}$ Therefore, the question should be reconsidered to make it more understandable and culturally suitable. The S-CVI of the HADS subscales, anxiety and depression, was above the recommended value $(0.90) .{ }^{30}$ Similarly, Zimmermann et a $a l^{29}$ stated that an S-CVI score above 0.83 is sufficient and satisfactory, indicating no ambiguity in understanding the questionnaire. The satisfactory S-CVI indicates cultural relevance.

The HADS/UV of both scales is comparable to previous studies ${ }^{12} 31$ and showed satisfactory internal consistency. The Cronbach alpha of HADS scales was good $(\alpha=0.84)$ and above recommended value and met Klines' criteria. ${ }^{20}$ The Cronbach alpha coefficient of the HADS subscales was good for anxiety $(\alpha=0.82)$ but below the recommended value for depression $(\alpha=0.64)$. By and large, the HADS-A subscale showed better psychometric properties than the HADS-D. ${ }^{13}$ Our study has reported good reliability scores; hence, we recommend that HADS/UV should be used in the clinical setting for screening of anxiety and depression in Pakistan.
Test-retest reliability was also excellent and intraclass correlation was 0.93 , which was similar to that of previous studies $^{32}$ and better than that of the Hyland et al study. ${ }^{21}$ The stability of the test-retest score over 2 weeks and high alpha coefficient support the strength of the HADS for use among pregnant women. Correlation between two factors, HADS-A and HADS-D, was excellent (0.667), similar to the Greek, ${ }^{33}$ Iranian, ${ }^{22}$ Arabic $^{26}$ and Pashto versions. ${ }^{9}$ The correlation was strong between HADS of both scales and the subscale scores. 212226

The EFA showed unequal distribution of items among the two factors, especially for factor 2. It was bidimensionally similar to the original English published by Zigmond and Snaith ${ }^{34}$ Majority of ex-studies documented the twofactor model, ${ }^{9} 121322232633$ and some reported three factors. ${ }^{20} 25$ Three exceptions were found, which reported a unidimensional model. ${ }^{23}$ In the EFA, most items of the HADS-A were loaded in factor 1 except for item 9 A5. A5 was also an unstable item and problematic in Iranian ${ }^{22}$ and $\mathrm{Arabic}^{26}$ translations. In contrast, item 14 (D7) was loaded less than 0.3 in factor 2 (depression); item ' $\mathrm{D} 7$ ' load remained $<0.3$ in factor 1 (anxiety). Items 'A4', 'D3' and 'A7' shared their loadings between factor 1 and 2. So, we would recommend that it is better to rephrase this item 14 (D7) in future studies as it asks about enjoying a good book, radio or TV programme, and it gave us mixed response due to the different medium of entertainment sources.

In turn, the extracted factors' correlation matrix showed no high correlation, typically between 0.03 and 0.545 , in the initial factor analysis, and very few items were highly correlated with others $(>0.50)$. Items 10 'D5' and item 14 'D7' correlated low $(>0.2)$ with most items. This irregularity of items' distribution and low correlation were observed in the Karimova and Martin ${ }^{31}$ study and suggests an unsatisfactory model and could be attributed to the impact of biological changes occurring during pregnancy on the perception of emotional components of the HADS. The explained variance of the HADS/UV is $42.75 \%$, which is quite similar to Waqas $e t a l^{2}$ and a bit far from the Watrowski and Rohde ${ }^{20}$ finding in the same population.

\section{Limitation}

This study has certain limitations; first, convergent and criterion validity were not done. Perhaps further validation approaches might be useful to test external validity of the HADS/UV. Second, the study sample was not representative of all three pregnancy trimesters.

\section{Implications}

The study revealed applicability of the HADS/UV as a screening tool to determine and measure depression and anxiety among pregnant women. Screening and early detection of psychological distresses, including anxiety and depression, will be very useful to overcome the burden associated with anxiety and depression. Healthcare workers can use this tool to predict early 
symptoms of anxiety and depression. Further validation studies in specific pregnancy trimesters are required.

\section{CONCLUSION}

Our study adds to the body of knowledge a proof about psychometric performance of HADS in obstetrics and gynaecology. The HADS/UV revealed satisfactory psychometric soundness; hence, it may be used as a robust screening tool to measure anxiety and depression in a population of pregnant women as it has shown stability of reliability over a time.

\section{Author affiliations}

${ }^{1}$ Community Medicine Department, Women Medical College, Abbottabad, Pakistan ${ }^{2}$ School of public Health, Department of Epidemiology and Biostatistics, Tehran University of Medical Sciences, Tehran, Iran

${ }^{3}$ Unit of Planning and Policy Formulation, Ministry of Health, Gaza Strip, Palestine ${ }^{4}$ Assistant professor, College of medical sciences, Israa university, Gaza strip, Palestine

${ }^{5}$ Department of Gynecology and Obstetrics, Ayub Medical College, Abbottabad, Pakistan

${ }^{6}$ Ministry of Health, Saudi Board Preventive Medicine, Mecca, Saudi Arabia

${ }^{7}$ Ministry of Health, Family Medicine Academy, Qassim, Saudi Arabia

Acknowledgements The authors are obliged to the Department of Gynecology and Obstetrics, Ayub Teaching Hospital, Abbottabad, for this research. We thank the participants for their cooperation. In addition, we express our deep appreciation to psychologists, doctors on duty, nursing staff and colleagues for their collaboration.

Contributors FSL, AME, SI and AAK made substantial contributions to the conception and design, analysis and interpretation of data. FSL, AME, UR and AAK were involved in drafting the manuscript and revising it critically for important intellectual content. FSL, AME and AAK gave the final approval of the version to be published. Each author participated sufficiently in the work and take public responsibility for appropriate portions of the content.

Funding The authors have not declared a specific grant for this research from any funding agency in the public, commercial or not-for-profit sectors.

Competing interests None declared.

Patient consent for publication Not required.

Ethics approval Permission was obtained from Ayub Teaching Hospital, Abbottabad. Objectives of the study were provided to participants and anonymity was ensured, and a signed consent form was obtained accordingly.

Provenance and peer review Not commissioned; externally peer reviewed.

Data availability statement Data are available upon reasonable request from the corresponding author.

Open access This is an open access article distributed in accordance with the Creative Commons Attribution Non Commercial (CC BY-NC 4.0) license, which permits others to distribute, remix, adapt, build upon this work non-commercially, and license their derivative works on different terms, provided the original work is properly cited, appropriate credit is given, any changes made indicated, and the use is non-commercial. See: http://creativecommons.org/licenses/by-nc/4.0/.

ORCID iD

Adeel Ahmed Khan http://orcid.org/0000-0003-2724-8113

\section{REFERENCES}

1 Sechrest L, Fay TL, Zaidi SMH. Problems of translation in crosscultural research. J Cross Cult Psychol 1972;3:41-56.

2 Sartorius N. Problems in translations in psychiatry-general problems. Eur Psychiatr 1994:13S-15.

3 Bullinger M, Anderson R, Cella D, et al. Developing and evaluating cross-cultural instruments from minimum requirements to optimal models. Qual Life Res 1993;2:451-9.
4 Prince R, Mombour W. A technique for improving linguistic equivalence in cross-cultural surveys. Int $J$ Soc Psychiatry 1967;13:229-37.

5 Werner O, Campbell DT. Translating, working through interpreters, and the problem of decentering. A handbook of method in cultural anthropology. , 1970: 398, 420.

6 Mokkink LB, Terwee CB, Patrick DL, et al. The COSMIN checklist for assessing the methodological quality of studies on measurement properties of health status measurement instruments: an international Delphi study. Qual Life Res 2010;19:539-49.

7 Terkawi A, Tsang S, AlKahtani G, et al. Development and validation of Arabic version of the hospital anxiety and depression scale. Saudi J Anaesth 2017;11:11-18.

8 Bjelland I, Dahl AA, Haug TT, et al. The validity of the hospital anxiety and depression scale. An updated literature review. J Psychosom Res 2002;52:69-77.

9 Irfan M, Sethi MR, Khan I, et al. Translation and validation in Pashto (1): Hospital anxiety and depression scale. JPMI 2017;31.

10 Lane DA, Jajoo J, Taylor RS, et al. Cross-cultural adaptation into Punjabi of the English version of the hospital anxiety and depression scale. BMC Psychiatry 2007;7:5.

11 Mumford DB, Tareen IA, Bajwa MA, et al. The translation and evaluation of an Urdu version of the hospital anxiety and depression scale. Acta Psychiatr Scand 1991;83:81-5.

12 Waqas A, Aedma KK, Tariq M, et al. Validity and reliability of the Urdu version of the Hospital Anxiety \& Depression Scale for assessing antenatal anxiety and depression in Pakistan. Asian J Psychiatr 2019

13 Risal A, Manandhar K, Linde M, et al. Reliability and validity of a Nepali-language version of the hospital anxiety and depression scale (HADS). Kathmandu Univ Med J 2015;13:115-24.

14 Thomas BC, Devi N, Sarita GP, et al. Reliability and validity of the Malayalam Hospital anxiety and depression scale (HADS) in cancer patients. Indian J Med Res 2005;122:395.

15 Medical teaching institution, Ayub teaching Hospital, Abbottabad. Available: http://ath.gov.pk/

16 Martin C. What does the hospital anxiety and depression scale (HADS) ReallyMeasure in liaison psychiatry settings? Curr. Psychiatry Rev 2005;1:69-73.

17 pp. Cosco TD, Doyle F, Ward M, et al. Latent structure of the hospital anxiety and depression scale: a 10-year systematic review. $J$ Psychosom Res 2012;72:180-4.

18 Kline P. The Handbook of psychological testing. London: Routledge, 1993.

19 Yaghmale F. Content validity and its estimation. J Med Educ 2003;3:25-7.

20 Watrowski R, Rohde A. Validation of the Polish version of the hospital anxiety and depression scale in three populations of gynecologic patients. Arch Med Sci 2014;10:517-24.

21 Hyland KA, Hoogland AI, Gonzalez BD, et al. Evaluation of the psychometric and structural properties of the Spanish version of the hospital anxiety and depression scale in Latina cancer patients. $J$ Pain Symptom Manage 2019;58:289-96.

22 Montazeri A, Vahdaninia M, Ebrahimi M, et al. The hospital anxiety and depression scale (HADS): translation and validation study of the Iranian version. Health Qual Life Outcomes 2003;1:14.

23 Reda AA. Reliability and validity of the Ethiopian version of the hospital anxiety and depression scale (HADS) in HIV infected patients. PLoS One 2011;6:16049.

24 Helvik A-S, Engedal K, Skancke RH, et al. A psychometric evaluation of the hospital anxiety and depression scale for the medically hospitalized elderly. Nord J Psychiatry 2011;65:338-44.

25 Wang W, Chair SY, Thompson DR, et al. A psychometric evaluation of the Chinese version of the hospital anxiety and depression scale in patients with coronary heart disease. $J$ Clin Nurs 2009;18:1908-15.

26 Al Aseri ZA, Suriya MO, Hassan HA, et al. Reliability and validity of the hospital anxiety and depression scale in an emergency department in Saudi Arabia: a cross-sectional observational study. BMC Emerg Med 2015;15:28.

27 el-Rufaie OE, Absood GH. Retesting the validity of the Arabic version of the hospital anxiety and depression (had) scale in primary health care. Soc Psychiatry Psychiatr Epidemiol 1995;30:26-31.

28 Martin CR, Thompson DR. Utility of the hospital anxiety and depression scale in patients with end-stage renal disease on continuous ambulatory peritoneal dialysis. Psychol Health Med 1999;4:369-76.

29 Zimmermann N, Küng K, Sereika SM, et al. Assessing the Safety Attitudes Questionnaire (SAQ), German language version in Swiss university hospitals--a validation study. BMC Health Serv Res 2013;13:347. 
30 Polit DF, Beck CT, Owen SV. Is the CVI an acceptable indicator of content validity? Appraisal and recommendations. Res Nurs Health 2007;30:459-67.

31 Karimova G, Martin C. A psychometric evaluation of the hospital anxiety and depression scale during pregnancy. Psychol Health Med 2003;8:89-103.

32 Herrmann C. International experiences with the Hospital Anxiety and Depression Scale--a review of validation data and clinical results. $J$ Psychosom Res 1997;42:17-41.
33 Michopoulos I, Douzenis A, Kalkavoura C, et al. Hospital anxiety and depression scale (HADS): validation in a Greek General Hospital sample. Ann Gen Psychiatry 2008;7:4.

34 Zigmond AS, Snaith RP. The hospital anxiety and depression scale. Acta Psychiatr Scand 1983;67:361-70.

35 Cicchetti DV. On a model for assessing the security of infantile attachment: issues of observer reliability and validity. Behav Brain Sci 1984;7:149-50.

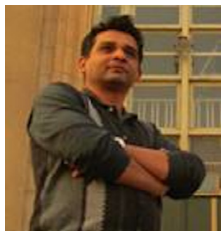

Fahad Saqib Lodhi obtained his master's degree on health from University of Health Sciences, Lahore, Pakistan, in 2010. He was awarded a scholarship in 2013 from Tehran University of Medical Sciences, Iran, and obtained a Ph.D degree on Epidemiology. He studied medicine at the Khyber Medical University, Peshawar, Pakistan. He is currently working as a Professor of Epidemiology at Community Medicine department in the Women Medical and Dental College, Abbottabad, Pakistan. His main research interests include quality of life, psychometric properties, epidemiology and women's health and family system. 